\title{
Societal contributors to cardio-metabolic diseases in Indigenous populations: an International Delphi study
}

\section{Published as: Principles and strategies for improving the prevention of cardio- metabolic diseases in indigenous populations: An international Delphi study in the journal Preventive Medicine}

Lee Stoner PhD, MPH'1,2,3*; Anna G. Matheson PhD ${ }^{1}$; Lane G. Perry PhD" Michelle A. Williams ScD, MPH ${ }^{5}$; Alexandra McManus PhD, MPH${ }^{6}$; Maureen Holdaway $\mathrm{PhD}^{7}$; Lyn Dimer${ }^{8}$; Jennie R. Joe PhD ${ }^{9}$; Andrew Maiorana $\mathrm{PhD}^{8,10}$

* Corresponding Author

1 School of Public Health, Massey University, Wellington, 6140, New Zealand.

2 School of Sport and Exercise, Massey University, Wellington, 6140, New Zealand.

3 School of Sport and Exercise, University of North Carolina at Chapel Hill, Chapel Hill, North Carolina, 27599, USA.

4 Center for Service Learning \& Department of Human Services, Western Carolina University, Cullowhee, 28723, USA.

5 Harvard T.H. Chan School of Public Health, Harvard University, Boston, Massachusetts, 02115.

6 Faculty of Health Sciences, Curtin University, Bentley, 6102, Australia.

7 Research Centre for Maori Health and Development, Massey University, Palmerston North, 442, New Zealand.

8 School of Physiotherapy and Exercise Science, Curtin University, Bentley, 6102, Australia.

9 Department of Family and Community Medicine, University of Arizona, Tuscon, Arizona, 85719, USA.

10 Department of Allied Health, Fiona Stanley Hospital, Murdoch, 6150 Australia.

* Corresponding Author: E: dr.l.stoner@gmail.com, T: +1.919.962.0534, F: +1.919.962.0489

Type of article: Original

Study design: Delphi

Word count: 3,464 (inc. in-text citations)

Word count abstract: 246

Figures: 1

Tables: 4

References: 53

Funding: none:

Conflict of interest: No financial disclosures were reported by the authors of this paper 


\section{Abstract}

The disparity in life expectancy between Indigenous and non-Indigenous populations is being driven by a heightened incidence of cardio-metabolic diseases, and is at least partly underpinned by educational, economic and historical determinants. However, there is a lack of consensus with regards to priorities for tackling these determinants. Therefore, the current study recruited experts in Indigenous cardio-metabolic health from Australia, New Zealand and the United States, in order to establish local consensus opinion and initiate dialogue. A three-round Delphi process was used to consolidate and compare the opinions of 60 experts, 20 from each country. Round one, the experts were asked three open-ended questions: (i) historical, (ii) economic and (iii) socio-cultural factors contributors to cardio-metabolic disease risk. Round two, the experts completed a structured questionnaire based on results from the first round, in which they ranked items according to their importance. Final round, the experts were asked to re-rank the same items after receiving summary feedback about the rank ordering from the previous round. Several key findings were identified: (i) an important historical factor is marginalization and disempowerment; (ii) in terms of economic and sociocultural factors, the panellists came to the consensus that socio-economic status and educational inequalities are important; (iii) while consensus was not reached, economic and educational factors also perceived to be historically influential. These findings support the need for multi-level health promotion policy. For example, tackling financial barriers that limit access to health-promoting resources, and improving literacy skills to permit understanding of health education.

Key words: cardiovascular; metabolic; Aboriginal; determinants of health; health policy; Australia; New Zealand; United States 


\section{Introduction}

The disparity in life expectancy between Indigenous and non-Indigenous populations in Australia (AU), New Zealand (NZ) and the United States (US) is being driven by heightened incidence of cardio-metabolic non-communicable diseases (ABS, 2006; Huffman and Galloway, 2010; MOH, 2007). Among Indigenous populations, the prevalence of cardiometabolic risk factors, the ability to pursue health lifestyle behaviors, access to health care, and the effectiveness of health promotion strategies have been linked to socio-ecological factors, including educational attainment and economic circumstance (Gibson et al., 2015; Huffman and Galloway, 2010; Katzenellenbogen et al., 2015). In turn, educational and economic circumstance have historical underpinnings (Cunningham and Stanley, 2003a; King et al., 2009).

The historical underpinnings of the health gap for many Indigenous groups began with colonization, particularly by Europeans (Cunningham and Stanley, 2003a; King et al., 2009) Following colonization, a common theme among the Indigenous populations of AU, NZ the US has been the dispossession of Indigenous lands and resources and vulnerability to exotic disease, leading to marginalization and dependency on the dominant settler culture (Cunningham and Stanley, 2003a; Jones, 2006; Voyle and Simmons, 1999). This marginalization has resulted in a loss of traditional lifestyle, but has also impacted access to employment, education, social services and adequate health care (Cunningham and Stanley, 2003a; Jones, 2006; Voyle and Simmons, 1999). The impacts of colonisation have persisted through generations with substantial health inequalities still evident today (Horton, 2006). The insidious and persistent health threats faced by Indigenous populations today are fuelled by the psycho-social and socioeconomic aftermath of dispossession (Voyle and Simmons, 1999). 
While significant research has recognized the importance of educational, economic and historical factors, there is a lack of consensus among influential stakeholders as to what should be the key priorities for tackling these challenges. This lack of consensus may be attributable to several factors. Firstly, the poor health status of Indigenous populations is caused by a complex combination of determinants (Gracey and King, 2009; King et al., 2009; WHO, 1986). Secondly, while common inequities are evident across Indigenous populations from different countries, there are some determinants unique to specific Indigenous populations. Lastly, there is a paucity of large-scale, methodologically rigorous interventions designed to improve indigenous health outcomes (Paul et al., 2010), and as such, there is a limited evidence base to guide the creation and prioritization of effective prevention strategies.

The purpose of the current study was to identify the perceived importance of educational, socioeconomic and historical factors to indigenous cardio-metabolic health. Influential stakeholders (academics, policy makers, public health practitioners, health workers) from AU, NZ and the US were surveyed using the Delphi Technique. The Delphi Technique was originally developed to bring clarity to a complex area in need of structure (Hsu and Sanford, 2007), and for this study was used to establish local consensus opinion and initiate dialogue with regards to the creation and prioritization of effective prevention strategies.

\section{Methods}

This observational study was carried out in accordance with STROBE (Strengthening the Reporting of Observational Studies in Epidemiology) guidelines (von Elm et al., 2007). 


\section{Study Design}

Data for the current study were collected as part of a larger study examining principles and strategies for improving the prevention of cardio-metabolic diseases in Indigenous populations (Castro et al., 2014; Stoner et al., 2017). With relevance to the current study, a three-round Delphi study was used to transform the opinions of a panel of anonymous experts into group consensus (Dalkey, 1969). The panelists were asked about (i) historical, (ii) economic and (iii) socio-cultural factors contributors to cardio-metabolic disease risk. For each round, the panelists were emailed a country-specific hyperlink to complete a web-based (Qualtrics, Utah, US) questionnaire. Panelists were given three weeks to complete each round, and were emailed a reminder on weeks two and three. Three weeks was allocated for analysis between rounds. Approval was obtained from the ethics committees of Massey University in NZ (MUHECN 14/052), Western Carolina University in the US (2015-0132), and Curtin University in AU (HR39/2015). The AU panelists completed an online consent form prior to participation, whereas for the NZ and US panelists consent to participate in the Delphi survey was implied by completion of the questionnaire.

\section{The Delphi Technique}

The Delphi Technique (Fig 1) is characterized by three features: anonymity; iterative and controlled feedback; and aggregation of responses. Anonymity reduces the effects of dominant individuals, a limitation of other group-based processes (Delbecq et al., 1986). For each round of questions the responses are summarized and controlled feedback provided to the experts before completing the subsequent questionnaire. This 'questionnaire-feedback' process encourages the panel to become more problem-solving oriented, minimizes noise, and is repeated until consensus has been obtained (Hsu and Sanford, 2007). While up to six 
rounds of questionnaires have been employed, three rounds are often sufficient to reach consensus (Wilson et al., 2003). For the purpose of the current study, consensus was defined as all three panels (AU, NZ, US) prioritizing an item.

\section{Expert Panel}

Experts were recruited from a range of disciplines to provide a wide breadth of perspectives from influential stakeholders. For inclusion on the panel, participants were required to meet at least two out of the following four criteria: i) published in Indigenous health; ii) extensive practical experience in Indigenous health; iii) demonstrated professional interest in Indigenous health; iv) considerable experience in Indigenous health management. An initial list of approximately fifty potential participants was composed from each country using snowball sampling. From the final list, twenty potential panel members from each country were selected, attempting to ensure adequate representation across the inclusion criteria (Delbecq et al., 1986). Contact was made with each of the potential panel members prior to initiating the study to ensure they met the criteria and were able to participate in all three rounds.

\section{Round 1 Questionnaire}

The first round of questions was exploratory (open-ended), serving as a cornerstone for soliciting specific information. Care was taken to ensure these broad questions were clearly understood by the panel, with the final draft sent to Indigenous consultants from each country $(\mathrm{NZ}=\mathrm{MH}, \mathrm{US}=\mathrm{JJ}, \mathrm{AU}=\mathrm{LD})$ for independent review.

The responses to each question from Round 1 were independently analyzed by the primary researcher from each country $(\mathrm{NZ}=\mathrm{LS}$, US = LP, AU = AM) using content 
analysis.(Silverman, 2009) To cluster the data about similar topic areas, like responses were grouped and appropriated to a theme. Subsequently, an auditor from each country (NZ = AM, $\mathrm{US}=\mathrm{JRJ}, \mathrm{AU}=\mathrm{AMc}$ ) was asked to analyze the grouped responses and approve or question the emergent themes. After this independent review the primary research team $(\mathrm{NZ}=\mathrm{LS}$, US $=\mathrm{LP}, \mathrm{AU}=\mathrm{AM}$ ) met to identify the 'core ideas' within each theme and reduce the data. The primary research team then discussed the core ideas until the group arrived at consensus regarding their content and wording, and converted the core ideas into questionnaire items. For each item an example attribute was assigned to ensure clarity, e.g., item = historical factors, attribute $=$ related to colonization and institutional racism. The final draft was then sent to an Indigenous consultant from each country $(\mathrm{NZ}=\mathrm{MH}, \mathrm{US}=\mathrm{JJ}, \mathrm{AU}=\mathrm{LD})$ for independent review.

\section{Round 2 Questionnaire}

The second round questionnaire retained the original twelve questions. However, rather than being open ended, each question had a number of closed-ended items (ranging from 7 - 10 items per question) based on the summary responses from Round 1 . The panelists were asked to select the top three items (priorities) to establish preliminary priorities, and to provide a rationale for their responses. Items prioritized by all three panels were regarded as key priorities. Any items not selected as a priority by at least one of the three panels was removed.

\section{Round 3 Questionnaire}

Each question for the final questionnaire included the top three items (priorities) for each country (5 items per question). The priorities were rank ordered, using the percentage of total responses across the three countries. For this round, the panelists were provided with the opportunity to revise their top three priorities. To determine the final ranking, the top three 
priorities from each panelist were scored: rank $1=3$ points, rank $2=2$ points, rank $3=1$ point. The priority with the highest total points allocation was rated as the highest priority.

\section{Results}

\section{Recruitment and Participants}

Sixty expert panellists, 20 from each country, agreed to participate, from which 40 panellists completed Round 1, 37 completed Round 2 and 35 completed Round 3. Demographic and occupational information for the panellists who completed Round 3 are reported in Table 1.

\section{Q1. Historical Factors}

Ten items emerged (Table 2), which were reduced to five following Round 2 and maintained through Round 3. One key priority emerged: a primary historical factor influencing cardiometabolic health is marginalization and associated disempowerment. Marginalization and disempowerment was regarded as the second lowest priority in Round 1, and the fourth highest priority following Round 2.

\section{Q2. Economic Factors}

Seven items emerged (Table 3), which were reduced to five following Round 2, and three following through Round 3. The panels came to the consensus that the most significant economic factors are: (i) poverty and poor employment opportunities (regarded as the key priority through all rounds); (ii) high costs of healthy foods; and (iii) educational inequalities. 


\section{Q3.Socio-Cultural Factors}

Nine items emerged (Table 4), which were reduced to five following Round 2, and four

following Round 3. Two key priorities emerged: the most important socio-cultural factors are:

(i) low SES (listed as a priority for Round 2 but not Round 1) ; and (ii) poor education.

\section{Key differences between countries}

The three panels agreed on the top three priorities for Q2 (economic factors), but only on one priority for Q3 (socio-cultural), and two factors for Q1 (historical). For Q3, only the AU panel recognized “factor related to mental health” as a key priority. For Q1, only the US recognized “educational inequalities” and discriminatory laws and policies” as a key priority.

\section{Discussion}

The purpose of this research was to facilitate dialogue on the creation and prioritization of strategies for improving Indigenous cardio-metabolic health. Specifically, the Delphi Technique was used to survey influential stakeholders and identify the perceived importance of educational, economic and historical factors. Several key themes emerged:

i. an important historical factor is marginalization and associated disempowerment;

ii. in terms of economic and socio-cultural factors, the panelists came to the consensus that economic status (socio-economic status, poverty, poor employment) and educational inequalities are important

iii. while consensus was not reached, economic and educational factors were also perceived to be historically important 


\section{Comparison with other studies}

It is well established that the Indigenous populations of AU, NZ, and the US have poorer health status than non-Indigenous populations across numerous measures of SES (ABS, 2011; SNZ, 2013; UCSB, 2011). For example, in NZ there is a greater proportion of the Indigenous population living in more deprived geographic areas, having lower household incomes, and attaining lower formal education than those of European-descent (MOH, 2014a). Low SES has also been associated with being less physically active, more time spent watching television, lower awareness of healthy nutrition, and consumption of a higher proportions of saturated fats and processed sugars $(\mathrm{MOH}, 2014 \mathrm{a})$. Some of the ways that SES can impact health include: (i) the high cost of healthy foods compared to convenience foods; (iii) low income families tend to live in neighborhoods with poor physical infrastructure, including less access to greenspaces and recreational facilities; (iii) low-income families may not be able to afford to compensate for poor neighborhood infrastructure by paying for alternative physical activities (Pearson et al., 2014). The importance of social-environmental determinants was recognized by panel members from each country, with one NZ panel member stating that there is a need to “...improve access to health promoting environments e.g., regulation of food, alcohol and tobacco, and provision of safe neighbourhoods that allow for improved outdoor activity”, and another from the US iterating the need to focus on “... upstream approaches, e.g., taxing sugar, no advertising [of] unhealthy food, [limit] children's TV”.

The Indigenous groups of AU, NZ, and the US attain substantially lower levels of education than their non-Indigenous counterparts (AIHW, 2014; MOE, 2015; NIEA, 2015). For example, in NZ only 59\% of the Indigenous population completed high school in 2014, compared to $81 \%$ of the European-descent population. The relationship between education and cardio-metabolic health parallel those for income, whereby lower levels of educational 
attainment are associated with a higher prevalence of cardiovascular risk factors, higher incidence of cardiovascular events, and higher cardiovascular mortality (Kaplan and Keil, 1993; Mackenbach et al., 2000; Mensah et al., 2005). Educational attainment may directly or indirectly influence health outcomes. An example of a more direct impact is where having less than a high school education has been associated with low health literacy, which in turn has been associated with poorer health outcomes (Berkman et al., 2011). While an example of an indirect impact is articulated by a NZ panelist "low education completion rates for Indigenous peoples reduce their chances of getting [a] well-paid job” resulting in lower income prospects (MOE, 2015). In turn, low income impedes access to nutritious food, safe housing, a good working environment and social participation (Dahlgren, 2007).

Although mental health issues did emerge as an economic factor for each sub-panel following Round 1, only AU ranked this factor as a priority in the final round. There is a wellestablished body of literature which documents associations between mental health and CVD risk (Barth et al., 2004; Rutledge et al., 2006; van Melle et al., 2004). However, the reason for mental health only being recognized as a priority by the AU sub-panel is unclear. Mental health disorders is a major issue for the Indigenous populations of each country, with each reporting approximately double the prevalence for Indigenous versus non-Indigenous groups (AIHW, 2014; CDC, 2011; MOH, 2014a, b). The AU panelist did state that Aboriginal Australians suffer from "high chronic inter-generational stress levels”, and that this may be “....a result of colonization and the stolen generation”. The AU panelists also stated that they continue to be treated “....as second class citizens (or not even citizens)”, and they are concerned about "top down decisions with lack of consultation with Indigenous people (e.g, NT [Northern Territory] Intervention; threat of closing remote communities)”. These remarks refer to the 'stress' of discriminatory policies which are in living memory, including: not 
being counted in the census until 1967 (AEC, 2006); various Acts of Parliament which permitted the "Stolen Generations" to occur between 1906 and 1969 (Read and New South Wales. Dept. of Aboriginal Affairs., 2006); and the currently enforced 2007 Northern Territory National Emergency Response, which, according to the United Nations, is racially discriminating and infringes on the human rights of Aboriginal people (Anya, 2010). Moreover, these remarks suggest the mental health first aid should be a particularly important component of health promotion in AU (Commission, 2015).

It has been argued that persistent and unequal health threats faced by Indigenous populations today are still influenced by the psycho-social and socioeconomic aftermath of the dispossession of Indigenous land and resources (Voyle and Simmons, 1999). Following dispossession, the Indigenous populations of AU, NZ, and the US were marginalized and became a minority culture within the colonial society (Cunningham and Stanley, 2003b; Jones, 2006; Voyle and Simmons, 1999). Marginalization not only led to loss of traditional lifestyle and exposure to exotic disease, but it also led to poor access to employment, education, social services and adequate health care (Cunningham and Stanley, 2003b; Jones, 2006; Voyle and Simmons, 1999). Health inequalities across numerous outcomes still persist in Indigenous populations, meaning these populations begin life with a lower baseline of opportunity (Horton, 2006). Moreover, they face forms of ‘institutional racism’ wherein government and other power systems systematically exclude or marginalize social groups (Paradies et al., 2008). Such marginalization limits political participation, reduces control over external influencers (Matheson et al., 2009), and presents a major barrier to selfdetermination and empowerment (Stoner et al., 2015). 


\section{Policy Implications}

The findings of the current study are in-line with the growing body of evidence demonstrating that health promotion strategies are unlikely to be successful if they are implemented in isolation of other interventions (Tricket et al., 2011). For example, indigenous groups are unlikely to access health-promoting resources if there are financial barriers, and are unlikely to digest health education without appropriate literacy skills. Therefore, it is unlikely that the Indigenous health gap will be resolved by tackling an independent factor, but rather requires an “holistic healthcare approach” (AU panelist) across “...multi levels” (NZ panelist) (Katzenellenbogen et al., 2015). According to one NZ panelist, "the causes of cardio metabolic diseases are complex and multi-faceted hence a similarly multi-level approach targeting Whānau [extended family] and community is required”. This is particularly important for Indigenous people without the financial means, health literacy or experience to navigate their way through Westernized healthcare systems.

While there is clear evidence supporting the need for multi-level health promotion strategies, there is still the question of who should be responsible for developing and funding policies to address the socio-economic and socio-cultural determinants of Indigenous health (Abdolhosseini et al., 2015). Considering the historical underpinnings of the health gap for many Indigenous groups began with colonization (Cunningham and Stanley, 2003a; King et al., 2009), an argument can be made that federal governments should claim direct responsibility. Such attempts have been made in NZ, where initiatives to support Māori development and improve health outcomes have been designed through central government, including actions through the Waitangi Tribunal to compensate Iwi (tribes) for the land that was taken from them by the European settlers (Ward, 1999). However, many question the role of government in providing services, arguing that Indigenous people should be supported in 
the development of their own solutions, rather than having solutions imposed on or provided for them (Abdolhosseini et al., 2015; Lowell et al., 2003). For example, in AU a history of discrimination and displacement from land, culture, and family has generated a feeling of mistrust among the Indigenous people (Holmes et al., 2002), and such mistrust may prevent the government from gaining sufficient traction to effectively address the Indigenous health gap. Arguably, where the government should claim responsibility is in funding and evaluating Indigenous healthcare and promotion initiatives. For instance, the implementation of the Apunipima Cape York Health Council, the largest community controlled health organization in the state of Queensland, AU, has led to increased access to healthcare services, and the serviced communities are outperforming the national key performance indicators.(Council) Further, in NZ there have also been policy attempts to enable local ownership of health services through Māori-for-Māori health providers in primary care (Slater et al., 2016). These localized examples are not exhaustive, and do not fully address the question as to who should be responsible for developing and funding Indigenous health policy; however, these examples do support the need for continued and deeper discourse.

\section{Strengths and limitations of this study}

This study had several potential limitations. First, the three panels (AU, NZ, US) did not come to consensus for two of the three questions. While an additional round could have been implemented, the lack of agreement is an important finding in itself, likely reflecting the unique historical, institutional, socio-cultural and environmental determinants of health experienced by each specific Indigenous group within their country context. These findings indicate that while Indigenous populations across AU, NZ and the US are facing a number of similar challenges, these populations are not monolithic and require tailored health prevention strategies. Second, there was attrition of panelists with each round, which may have reduced 
the breadth of opinions in subsequent rounds. Nonetheless, the attrition was minimal $(n=5)$ and was unlikely to have resulted in substantial bias. Last, the opinions of the respondents may not be representative of all influential stakeholders. However, every attempt was made to ensure broad representation, and we believe that the opinions generated by this study are valuable in stimulating necessary dialogue.

\section{Conclusion}

The Delphi Technique was used to survey influential stakeholders and identify the perceived importance of educational, economic and historical factors to indigenous cardio-metabolic health. Several key themes emerged: (i) an important historical factor is marginalization leading to disempowerment; (ii) in terms of economic and socio-cultural factors, the panelists came to the consensus that economic status and educational inequalities are important; (iii) the experts did not full agree on the most important historical and socio-cultural factors. The lack of full agreement supports the notion that poor Indigenous cardio-metabolic health is a ‘complex problem’ with many causative factors, and that health prevention strategies are unlikely to be successful if they are implemented in isolation of other interventions. Further, while economic and educational inequalities are important targets, intervention strategies should be contextualized to the local Indigenous populations.

\section{Declarations}

\section{Abbreviations}

AU, Australia; NZ, New Zealand, SES, socio-economic status; US, United States

\section{Acknowledgements}

We would like to thank each panel member who agreed to participate in this study. 


\section{Funding}

None to declare.

\section{Competing interests}

All authors declare: no support from any organisation for the submitted work; no financial relationships with any organisations that might have an interest in the submitted work in the previous three years; no other relationships or activities that could appear to have influenced the submitted work

\section{Author Contributors}

LS, AM, LGP and AMc designed the initial survey. LS, AM and LGP analysed the findings. MH, JRJ and LD provided indigenous consultation. AGM, JRJ, and AMc audited the responses the responses from round one. All authors participated in the analysis and interpretation of the data, revision of the article, and final approval of the version to be published. LS is the guarantor. All authors had full access to all of the data, including statistical reports and tables, and can take responsibility for the integrity of the data and the accuracy of the data analysis.

\section{Ethical approval}

Approval was obtained from the ethics committees of Massey University in NZ (MUHECN 14/052), Western Carolina University in the US (2015-0132), and Curtin University in AU (HR39/2015).

\section{Data sharing}


All data generated or analysed during this study are included in this published article and its supplementary information files. 


\section{References}

Abdolhosseini, P., Bonner, C., Montano, A., Young, Y. Y., Wadsworth, D., Williams, M., Stoner, L., 2015. Should the governments of 'developed' countries be held responsible for equalizing the indigenous health gap? Glob Health Promot.

Australian Bureau of Statistics (ABS). 2006. National Aboriginal and Torres Strait Islander health survey, 200405.

2011. 2076.0 - Census of Population and Housing: Characteristics of Aboriginal and Torres Strait Islander Australians, 2011. Available online at http://www.abs.gov.au/ausstats/abs@.nsf/Lookup/2076.0main+features602011. last accessed on Oct 19 2015

AEC, 2006. History of the indigenous vote. Australian Electoral Commission, Kingston, ACT.

Australian Institute of Health and Welfare (AIHW). 2014. Australia's Health 2014.

United Nations. 2010. Observations On The Northern Territory Emergency Response In Australia.

Barth, J., Schumacher, M., Herrmann-Lingen, C., 2004. Depression as a risk factor for mortality in patients with coronary heart disease: a meta-analysis. Psychosom Med 66:802-13.

Berkman, N. D., Sheridan, S. L., Donahue, K. E., Halpern, D. J., Crotty, K., 2011. Low health literacy and health outcomes: an updated systematic review. Ann Intern Med 155:97-107.

Castro, N., Faulkner, J., Skidmore, P., Williams, M., Lambrick, D. M., Signal, L., Thunders, M., Muller, D., Lark, S., et al., 2014. Pre-adolescent cardio-metabolic associations and correlates: PACMAC methodology and study protocol. BMJ open 4:e005815.

Centres for Disease Control (CDC). 2011. Health Data Interactive: Mental health, serious psychological distress, ages 18+: US, 1997-2011. Available online at http://205.207.175.93/HDI/TableViewer/tableView.aspx?ReportId=455. last accessed on Oct 202015

Government of Western Australia Mental Health Commission

2015. Aborginal mental health. Available online at http://www.mentalhealth.wa.gov.au/mental_illness_and_health/mh_aboriginal.aspx. last accessed on Nov 62015

Apunipima Cape York Health Council. Available online at http://www.apunipima.org.au/about. last accessed on Oct 202015

Cunningham, C., Stanley, F., 2003a. Indigenous by definition, experience, or world view. British Medical Journal 327:403-4.

Cunningham, C., Stanley, F., 2003b. Indigenous by definition, experience, or world view. BMJ 327:403-4.

WHO Regional Office for Europe. 2007. European strategies for tackling social inequities in health: levelling up, Part 2.

Dalkey, Norman Crolee, 1969. The Delphi method : an experimental study of group opinion. Rand Corp. : Distributed by Clearinghouse for Federal Scientific and Technical Information, U.S. Dept. of Commerce, National Bureau of Standards, Institute for Applied Technology, Santa Monica, Calif.

Delbecq, Andre L., Van de Ven, Andrew H., Gustafson, David H., 1986. Group techniques for program planning : a guide to nominal group and delphi processes. Green Briar Press.

Gibson, O., Lisy, K., Davy, C., Aromataris, E., Kite, E., Lockwood, C., Riitano, D., McBride, K., Brown, A., 2015. Enablers and barriers to the implementation of primary health care interventions for Indigenous people with chronic diseases: a systematic review. Implement Sci 10:71.

Gracey, M., King, M., 2009. Indigenous health part 1: determinants and disease patterns. Lancet 374:65-75.

Holmes, W., Stewart, P., Garrow, A., Anderson, I., Thorpe, L., 2002. Researching Aboriginal health: experience from a study of urban young people's health and well-being. Soc Sci Med 54:1267-79.

Horton, R., 2006. Indigenous peoples: time to act now for equity and health. Lancet 367:1705-7.

Hsu, C-C., Sanford, B.A, 2007. The Delphi Technique: Making Sense Of Consensus. Practical Assessment, Research \& Evaluation, 12:1-8.

Huffman, M. D., Galloway, J. M., 2010. Cardiovascular health in indigenous communities: successful programs. Heart Lung Circ 19:351-60.

Jones, D. S., 2006. The persistence of American Indian health disparities. Am J Public Health 96:2122-34.

Kaplan, G. A., Keil, J. E., 1993. Socioeconomic factors and cardiovascular disease: a review of the literature. Circulation 88:1973-98.

Western Australian Centre for Rural Health, University of Western Australia;. 2015. Information for Action: Improving the Heart Health Story for Aboriginal People in Western Australia (BAHHWA Report).

King, M., Smith, A., Gracey, M., 2009. Indigenous health part 2: the underlying causes of the health gap. Lancet 374:76-85.

Cooperative Research Centre for Aboriginal and Tropical Health. 2003. Indigenous Health and Education: Exploring the Connections, . 
Mackenbach, J. P., Cavelaars, A. E., Kunst, A. E., Groenhof, F., 2000. Socioeconomic inequalities in cardiovascular disease mortality; an international study. Eur Heart J 21:1141-51.

Matheson, Anna, Dew, Kevin, Cumming, Jackie, 2009. Complexity, evaluation and the effectiveness of community-based interventions to reduce health inequalities Health Promotion Journal of Australia 20:221-26.

Mensah, G. A., Mokdad, A. H., Ford, E. S., Greenlund, K. J., Croft, J. B., 2005. State of disparities in cardiovascular health in the United States. Circulation 111:1233-41.

Ministry of Education (MOE). 2015. School leavers with NCEA Level 2 or above.

Ministry of Health (MOH). 2007. Mortality and Demographic Data 2004.

Ministry of Health (MOH). 2014a. Annual Update of Key Results 2013/14: New Zealand Health Survey. Available online at http://www.health.govt.nz/publication/annual-update-key-results-2013-14-newzealand-health-survey. last accessed on March 302015

Ministry of Health (MOH). 2014b. Mental Health and Addiction: Service use 2011/12.

National Indian Education Assoication (NIEA). 2015. Statistics on Native Students. Available online at http://www.niea.org/research/statistics.aspx\#Grad. last accessed on Oct 182015

Cooperative Research Centre for Aboriginal Health. 2008. The Impact of Racism on Indigenous Health in Australia and Aotearoa:Towards a Research Agenda, Discussion Paper No. 4.

Paul, C. L., Sanson-Fisher, R., Stewart, J., Anderson, A. E., 2010. Being sorry is not enough: the sorry state of the evidence base for improving the health of indigenous populations. Am J Prev Med 38:566-8.

Pearson, Amber, Betham, Graham, Day, Peter, Kingham, Simon, 2014. Associations between neighborhood environmental characteristics and obesity and realted behaviours amongst adult New Zealanders. BMC Public Health 14.

Read, Peter, New South Wales. Dept. of Aboriginal Affairs., 2006. The stolen generations : the removal of Aboriginal children in New South Wales 1883-1969, 7th reprint. ed. NSW Dept. of Aboriginal Affairs, Surry Hills, N.S.W.

Rutledge, T., Reis, V. A., Linke, S. E., Greenberg, B. H., Mills, P. J., 2006. Depression in heart failure a metaanalytic review of prevalence, intervention effects, and associations with clinical outcomes. J Am Coll Cardiol 48:1527-37.

Silverman, David, 2009. Doing qualitative research : a practical handbook, 3rd ed. SAGE, London.

Slater, T., Matheson, A., Davies, C., Goodyer, C., Holdaway, M., Ellison-Loschmann, L., 2016. The role and potential of community-based cancer care for Maori in Aotearoa/New Zealand. N Z Med J 129:29-38.

Statistics New Zealand (SNZ). 2013. 2013 Census QuickStats about income. Available online at http://www.stats.govt.nz/Census/2013-census/profile-and-summary-reports/quickstats-income/personalincome-ethnic.aspx. last accessed on Oct 192015

Stoner, L., Matheson, A. G., Perry, L. G., Williams, M. A., McManus, A., Holdaway, M., Dimer, L., Joe, J. R., Maiorana, A., 2017. Principles and strategies for improving the prevention of cardio-metabolic diseases in indigenous populations: An international Delphi study. Prev Med 96:106-12.

Stoner, L., Page, R., Matheson, A., Tarrant, M., Stoner, K., Rubin, D., Perry, L., 2015. The indigenous health gap: raising awareness and changing attitudes. Perspect Public Health 135:68-70.

Tricket, Edison, Beehler, Sarah, Deutsch, Charles, Green, Lawrence, Hawe, Penelope, McLeroy, Kenneth, Miller, Robin, Rapkin, Bruce, Schensul, Jean, et al., 2011. Advancing the science of community-level interventions. Framing Health Matters 101:1410-19.

2011. American Indian and Alaska Native Heritage Month: November 2011. Available online at https://www.census.gov/newsroom/releases/archives/facts_for_features_special_editions/cb11ff22.html. last accessed on Oct 192015

van Melle, J. P., de Jonge, P., Spijkerman, T. A., Tijssen, J. G., Ormel, J., van Veldhuisen, D. J., van den Brink, R. H., van den Berg, M. P., 2004. Prognostic association of depression following myocardial infarction with mortality and cardiovascular events: a meta-analysis. Psychosom Med 66:814-22.

von Elm, E., Altman, D. G., Egger, M., Pocock, S. J., Gotzsche, P. C., Vandenbroucke, J. P., Initiative, Strobe, 2007. The Strengthening the Reporting of Observational Studies in Epidemiology (STROBE) statement: guidelines for reporting observational studies. Lancet 370:1453-7.

Voyle, J. A., Simmons, D., 1999. Community development through partnership: promoting health in an urban indigenous community in New Zealand. Soc Sci Med 49:1035-50.

Ward, Alan, 1999. An unsettled history : treaty claims in New Zealand today. Bridget Williams Books, Wellington, N.Z.

1986. Ottawa charter for health promotion.

Wilson, A., Averis, A., Walsh, K., 2003. The influences on and experiences of becoming nurse entrepreneurs: a Delphi study. Int J Nurs Pract 9:236-45. 


\section{Table Legends}

Table 1. Demographic and occupational characteristics of participating experts who completed the final round

Table 2. Local panel rankings for question 1: The most significant historical factors contributing to cardio-metabolic disease risk in Indigenous people

Table 2. Local panel rankings for question 2: The most significant historical factors contributing to cardio-metabolic disease risk in Indigenous people

Table 4. Local panel rankings for question 3: The most significant socio-cultural factors contributing to cardio-metabolic disease risk in Indigenous people

\section{Figure Legends}

Fig 1. Outline of the Delphi process 
Table 1. Demographic and occupational characteristics of participating experts who completed the final round

\begin{tabular}{|c|c|c|c|c|c|c|}
\hline & $\mathrm{AU}$ & NZ & US & Total & $\%$ \\
\hline \multicolumn{2}{|l|}{$\mathrm{N}$} & 13 & 12 & 10 & 35 & 100 \\
\hline \multirow[t]{3}{*}{ Sex } & Male & 4 & 4 & 2 & 10 & 29 \\
\hline & Female & 9 & 7 & 8 & 24 & 69 \\
\hline & NR & 0 & 1 & 0 & 1 & 3 \\
\hline \multirow[t]{6}{*}{ Age (yrs) } & $<25$ & 0 & 0 & 0 & 0 & 0 \\
\hline & $25-34$ & 0 & 0 & 0 & 0 & 0 \\
\hline & $35-44$ & 3 & 3 & 0 & 6 & 17 \\
\hline & $45-54$ & 4 & 4 & 3 & 11 & 31 \\
\hline & $55-64$ & 7 & 4 & 5 & 16 & 46 \\
\hline & $64+$ & 1 & 1 & 2 & 4 & 11 \\
\hline \multirow[t]{6}{*}{ Ethnicit(ies) } & Caucasian & 10 & 3 & 6 & 19 & 54 \\
\hline & Indigenous & 3 & 7 & 4 & 14 & 40 \\
\hline & Pasifika & 0 & 1 & 0 & 1 & 3 \\
\hline & Hispanic & 0 & 0 & 1 & 1 & 3 \\
\hline & African American & 0 & 0 & 1 & 1 & 3 \\
\hline & NR & 0 & 1 & 0 & 1 & 3 \\
\hline \multirow[t]{5}{*}{ Language(s) } & English & 13 & 12 & 9 & 34 & 97 \\
\hline & Indigenous & 0 & 6 & 0 & 6 & 17 \\
\hline & Spanish & 0 & 0 & 1 & 1 & 3 \\
\hline & French & 0 & 1 & 1 & 2 & 6 \\
\hline & Tongan & 0 & 1 & 0 & 0 & 0 \\
\hline \multirow[t]{8}{*}{ Profession } & Academic & 7 & 7 & 7 & 21 & 60 \\
\hline & Medic & 1 & 2 & 0 & 3 & 9 \\
\hline & Nurse & 2 & 0 & 1 & 3 & 9 \\
\hline & Health Promoter & 1 & 0 & 0 & 1 & 3 \\
\hline & Health Service Provider & 3 & 1 & 0 & 4 & 11 \\
\hline & Hospital Admin & 0 & 0 & 1 & 1 & 3 \\
\hline & Unemployed & 0 & 1 & 0 & 1 & 3 \\
\hline & NR & 0 & 1 & 0 & 1 & 3 \\
\hline
\end{tabular}


Table 2. Local panel rankings for question 1: The most significant historical factors contributing to cardio-metabolic disease risk in Indigenous people

\begin{tabular}{|c|c|c|c|c|c|c|c|}
\hline \multirow[t]{2}{*}{ Item } & \multirow{2}{*}{$\begin{array}{l}\text { Rd 1 } \\
n=40\end{array}$} & \multirow{2}{*}{$\begin{array}{l}\text { Rd } 2 \\
n=37\end{array}$} & \multirow{2}{*}{$\begin{array}{l}\text { Rd 3 } \\
n=35\end{array}$} & \multicolumn{2}{|c|}{ Ranking } & \multirow[b]{2}{*}{$\mathbf{N Z}$} & \multirow[b]{2}{*}{ US } \\
\hline & & & & All & AU & & \\
\hline Colonization & 69 & 21 & 23 & 1 & 2 & 1 & \\
\hline Economic inequalities & 13 & 28 & 25 & 2 & 1 & 2 & \\
\hline Marginalization and disempowerment & 2 & 18 & 23 & 3 & 3 & 3 & 1 \\
\hline Educational inequalities & 9 & 20 & 20 & & & & 2 \\
\hline Discriminatory laws and policies & 9 & 12 & 14 & & & & 3 \\
\hline Discriminatory health services & 1 & 16 & & & & & \\
\hline Racism & 21 & 10 & & & & & \\
\hline Psychological trauma & 14 & 9 & & & & & \\
\hline Loss of family structure & 3 & 7 & & & & & \\
\hline Genetic predisposition & 8 & 6 & & & & & \\
\hline
\end{tabular}

$\mathrm{n}=$ number of times a response was listed for a given theme. Note for Round One: For a given theme, a panelist member may have provided more than one response, e.g., a panelist may have stated (i) loss of traditional lifestyle and (ii) loss of land, for 'colonization'. 
Table 3. Local panel rankings for question 2: The most significant economic factors contributing to cardio-metabolic disease risk in Indigenous people

\begin{tabular}{|c|c|c|c|c|c|c|c|}
\hline \multirow[t]{2}{*}{ Item } & \multirow{2}{*}{$\begin{array}{l}\mathrm{Rd} 1 \\
\mathrm{n}=40\end{array}$} & \multirow{2}{*}{$\begin{array}{l}\mathbf{R d} 2 \\
\mathrm{n}=37\end{array}$} & \multirow{2}{*}{$\begin{array}{l}\mathrm{Rd} 3 \\
\mathrm{n}=35\end{array}$} & \multicolumn{2}{|c|}{ Ranking } & \multirow[b]{2}{*}{ NZ } & \multirow[b]{2}{*}{ US } \\
\hline & & & & All & $\mathbf{A U}$ & & \\
\hline Poverty and poor employment opportunities & 52 & 31 & 34 & 1 & 1 & 1 & 1 \\
\hline High costs of healthy foods & 15 & 26 & 29 & 2 & 2 & 2 & 2 \\
\hline Educational inequalities & 6 & 23 & 27 & 3 & 3 & 3 & 3 \\
\hline High cost of housing & 10 & 17 & 11 & & & & \\
\hline Cost of healthcare & 9 & 14 & 3 & & & & \\
\hline Related to colonization & 3 & 13 & & & & & \\
\hline High costs of recreation facilities & 9 & 9 & & & & & \\
\hline
\end{tabular}

$\mathrm{n}=$ number of times a response was listed for a given theme. Note for Round One: For a given theme, a panelist member may have provided more than one response, e.g., a panelist may have stated (i) low household income and (ii) low minimum wage, for 'poverty and poor employment opportunities'. 
Table 3. Local panel rankings for question 2: The most significant economic factors contributing to cardio-metabolic disease risk in Indigenous people

\begin{tabular}{|c|c|c|c|c|c|c|c|}
\hline \multirow[t]{2}{*}{ Item } & \multirow{2}{*}{$\begin{array}{l}\text { Rd 1 } \\
n=40\end{array}$} & \multirow{2}{*}{$\begin{array}{l}\mathbf{R d} 2 \\
\mathrm{n}=37\end{array}$} & \multirow{2}{*}{$\begin{array}{l}\mathbf{R d} 3 \\
\mathrm{n}=35\end{array}$} & \multicolumn{2}{|c|}{ Ranking } & \multirow[b]{2}{*}{ NZ } & \multirow[b]{2}{*}{ US } \\
\hline & & & & All & $\mathbf{A U}$ & & \\
\hline Low socio-economic status & 4 & 25 & 30 & 1 & 1 & 1 & 1 \\
\hline Poor education & 4 & 19 & 24 & 2 & 3 & 2 & 2 \\
\hline Loss of cultural identity & 24 & 18 & 17 & 3 & & 3 & 3 \\
\hline Factors related to mental health issues & 5 & 16 & 13 & & 2 & & \\
\hline Neighborhood deprivation & 7 & 18 & 18 & & & & \\
\hline Lack of culturally aware Indigenous medical practitioners & 9 & 15 & & & & & \\
\hline Racism & 21 & 12 & & & & & \\
\hline Loss of family structure & 2 & 9 & & & & & \\
\hline Poor role models & 2 & 9 & & & & & \\
\hline
\end{tabular}

$\mathrm{n}=$ number of times a response was listed for a given theme. Note for Round One: For a given theme, a panelist member may have provided more than one response, e.g., a panelist may have stated (i) low SES and (ii) material deprivation, for 'colonization'. 
Definition of Problem

What strategies should be implemented to improve the prevention and management of noncommunicable diseases

Selection of Experts

Sixty experts identified, 20 from each $\mathrm{AU}, \mathrm{NZ}$ and the US

\section{Delphi Round 1}

Web-based 12 item open-ended questionnaire $(n=40)$. Content analysis to identify emergent themes.

\section{Delphi Round 2}

Panellist identify top 3 items for each of the original 12 questions $(n=37)$.

\section{Delphi Round 3}

Panellist rescore agreement for items in light of the group responses $(n=35)$.

Fig 1. Outline of the Delphi process 